\title{
A Review of the Use of Fine-Needle Aspiration Biopsy of Mammary Tumors for Diagnosis and Research
}

\author{
Edneia Tani Nelson Fuentes-Martinez Lambert Skoog \\ Department of Pathology and Cytology, Karolinska University Hospital Solna, Stockholm, Sweden
}

\section{Keywords}

Fine-needle aspiration cytology · Breast cytology · Cytology technique

\begin{abstract}
The article "Aspiration Biopsy of Mammary Tumors in Diagnosis and Research - A Critical Review of 2,200 Cases" by Zajicek et al. [Acta Cytol 1967;11:169-175] is composed of two separate parts as can be seen from the title. Both are, however, of great historical interest. The first describes the early days of fine-needle aspiration cytology diagnosis of breast lesions in particular carcinomas. The results are still impressive with a diagnostic accuracy close to $90 \%$. The second deals with the effect of negative pressure on cell viability during the aspiration procedure. These studies were aimed at evaluating the usefulness of aspirated tumor cells to analyze the effects of therapy and the origin of tumor cells.
\end{abstract}

(C) 2017 S. Karger AG, Basel

The accuracy of fine-needle aspiration (FNA) cytology in the diagnosis of breast lesions is based on the results of a study on 2,200 patients diagnosed between 1955 and 1962 [1]. To a large extent, this represented the work of (c) 2017 S. Karger AG, Basel

E-Mail karger@karger.com

www.karger.com/acy the pioneer of FNA cytology, Dr. Sixten Franzén (19192008). From Figure 3 in this original article, it can be seen that relatively few patients, around 50 each year, were diagnosed between 1955 and 1959. After that, the number increased dramatically and reached over 900 in 1962. However, the early introduction of FNA in tumor diagnosis at Radiumhemmet, Karolinska Hospital, Stockholm, Sweden, took place in 1950 already, with the cases just not being registered properly before 1955 .

The technique used for FNA biopsy was similar to that used in many institutions today, but the equipment was different, as can be seen from Figure 1. The one-handedgrip apparatus was used for aspiration by Sixten Franzén. The syringe was of glass and was nondisposable, which necessitated arduous cleaning by the technical staff. The 22 -gauge needles were also nondisposable, and had to be cleaned after being used as well as being sharpened at regular intervals. Gloves were not used due to high costs.

The equipment used in the FNA cytology clinic may be outdated, but the diagnostic work is still first-rate. In 980 patients, the FNA cytologic diagnosis was not followed by surgery. In 764 of these patients, various benign lesions were diagnosed. The remaining 216 had inoperable carcinomas, thus representing $10 \%$ of all patients in the study. Today, inoperable carcinomas are rare in most 
developed countries as a result of many factors, such as screening mammography and high awareness among patients and doctors.

In 1,220 patients, the cytologic diagnosis was followed by surgery and histopathology. Benign histologic diagnoses were reported in 542 patients; in $96 \%$ of these, the cytologic diagnosis was benign. No false positive cytologic diagnosis was given.

A histopathologic diagnosis of cancer was reported in 645 patients. The FNA cytologic diagnosis was cancer or suspicious for cancer in $88.9 \%$. In $9.1 \%$ of the cases, the cytologic material was nondiagnostic, reported as being due to unsatisfactory specimens. From the results presented, it can be seen that the percent of false-negative cytology decreased markedly with the increasing experience of the cytologist. This is an excellent example of a "learning curve."

The excellent performance of FNA cytology in the diagnosis of breast lesions was confirmed in several simultaneous articles by Franzén and Zajicek [2-4]. This slowly led to the acceptance of FNA cytology as a valuable procedure in the diagnostic workup of patients with breast lesions.

Today, FNA cytology has been replaced by core-needle biopsy in some institutions. In the first instance, this can, to a large extent, be explained by the lack of interest shown by pathologists in obtaining the proper training in the FNA procedure and the interpretation of the cytologic smears. This reluctance inevitably results in low diagnostic accuracy and the abandonment of the FNA procedure. Secondly, a preoperative analysis of proliferation rate, hormone receptor content, and Her2 status is often required for the correct choice of therapy. Without proficiency in the FNA cytology procedure, this is difficult to achieve. There are, however, many institutions in which breast cytology is still the first approach in the diagnosis of breast lesions. In addition, aspirated cells offer an excellent material for the evaluation of biomarkers, with both immunocytochemistry and in situ hybridization $[5,6]$.

The second part of the article describes the effect of negative pressure on cell viability during the aspiration procedure. This study was designed by Josef Zajicek (1923-1979), who, at the time, focused his research on using aspirated cells for the analysis of cellular enzymes as markers of malignancy and identifying the site of origin in metastatic cancer. In addition, the viability of aspirated cells as measured by dye exclusion after radiotherapy was studied to evaluate the effect of therapy. Figure 2 shows the elaborate apparatus for registering pressure differences during the biopsy procedure. In lymphocytes aspirated from a rat spleen, the viability was around $90 \%$ when the negative pressure was $80 \mathrm{~mm} \mathrm{Hg}$, as shown in Figure 5. From this figure, it can also be seen that a negative pressure of $760 \mathrm{~mm} \mathrm{Hg}$ resulted in a decrease of viability, to approximately $75 \%$. In contrast, cells aspirated from a series of 29 mammary carcinomas showed a much lower viability. Thus, in $50 \%$ of the cases, the viability was lower than 30\%, as presented in Figure 6.

The use of aspirated cells for biological work continued for some years and resulted in several scientific reports. The cellular content of alkaline phosphatase was analyzed in cells aspirated from fibroadenomas and mammary carcinomas [7]. The enzyme level was 2-4 times higher in fibroadenomas than in carcinomas. In addition, the effect of radiotherapy on cell permeability was studied in cells aspirated from a metastatic squamous carcinoma and lymphoblastic lymphoma. Somewhat unexpectedly, the cells from the radioresistant squamous cell carcinoma increased their permeability. In contrast, the cells from the lymphoblastic lymphoma (which regressed completely after 11 days of radiation therapy) showed no increase in permeability.

Moreover, in a separate article, Esposti et al. [8] showed that cells aspirated from a prostatic carcinoma had lower levels of acid phosphatase than benign prostatic cells. The cellular content of acid phosphatase in cells from thyroid and mammary tumors was barely detectable, and it was suggested that this difference could be of value in the identification of metastatic prostatic carcinoma. In 1976, aspirated cells were used for measuring DNA synthesis by ${ }^{3} \mathrm{H}$-thymidine incorporation in patients treated with endocrine therapy for mammary carcinoma [9]. This produced promising results, but could not be introduced in routine work because of the laborious technique including autoradiography. After this, the interest in enzymatic reactions in aspirated cells diminished because the technique was difficult to reproduce, required microgram quantities of cells, and was time consuming.

The introduction of immunocytochemistry obliterated these problems since it was reproducible and analysis was possible from examimning less than 100 cells. This technique was established in the Karolinska Hospital Cytology Clinic early in 1980, to analyze hormone receptors, cell proliferation and clonality, and the subclassification of lymphomas [10-13]. These studies thus followed up Zajicek's intentions to give a preoperative biological characterization of tumors on FNA material.

However, let's go back to around 1970. The aspiration clinic attracted many patients and it was impossible for 
Sixten Franzén (an oncologist with no training in histopathology) to cope single-handedly with this task. So Torsten Löwhagen (trained in histopathology and an excellent teacher) was recruited and, together with Josef Zajicek (trained in histopathology and with a sharp intellect), they formed an ideal team. Franzén and Löwhagen were dedicated clinicians who examined the patients, performed the FNA biopsies, and read the slides. This concept, i.e., that a pathologist examines a referred patient, performs the FNA biopsy, and reads the slides, has been referred to as "the Karolinska Model". Franzén had diagnosed and collected a large number of cases which Zajicek catalogued and compared to histopathology. Numerous scientific articles were published, several international courses given, and textbooks written on the subject. This work became the basis for the acceptance of FNA cytology in routine clinical work worldwide. These three men had different talents and personalities, but together they became the Titans of modern FNA cytology.

\section{Disclosure Statement}

The authors have no conflicts of interest to declare. 


\title{
Aspiration Biopsy of Mammary Tumors in Diagnosis and Research-A Critical Review of 2,200 Cases
}

\author{
J. Zajicek, M.D., S. Franzén, M.D., P. Jakobsson, M.D., C. Rubio, M.D., \\ AND B. UNSGAARD, M.D. \\ Cytology Department of Radiumhemmet, Institute of Radiopathology and the General Department of Radiumiremmet, \\ Karolinska Sjukhuset, Stockholm, Sweden
}

Aspiration biopsy can be defined as a procedure in which negative pressure is created in a syringe and, as a result of pressure difference, cellular material is drawn into the needle. It has long been an accepted method of obtaining material from blood-forming tissues for diagnostic purposes. More recently the method has been utilized also in the diagnosis of human tumours in various organs, including the breast, prostate, thyroid, salivary glands and lungs. ${ }^{1-5}, 8,10-13,15-20.24$ The number of aspiration biopsies performed annually at Radiumhemmet in Stockholm has reached about 6,000 and is still rising. In the present paper our results obtained in diagnosing the lesions of the breast are reported.

Aspirates obtained from human carcinomas through a fine (22 gauge) needle consist largely of plugs of epithelial cells mixed with interstitial fluid and variable amounts of blood. In earlier investigations $^{2,10,25}$ the epithelial component was isolated by means of centrifugation for quantitative enzyme analysis. Dipeptidase and acid and alkaline phosphatase activities were determined in cells aspirated from mammary and prostatic carcinomas. These value; were compared with results from analyses of epithelial plugs aspirated from benign mammary and prostatic lesions.

Since patients experience relatively little discomfort from aspiration biopsy with a fine needle, repeated biopsies are readily permitted. The method therefore provides a means of studying the biologic behaviour of tumour-cell populations during, for instance, radiotherapy or chemotherapy. 14

Use of aspiration biopsy for biologic studies, however, raises the question of whether or not the procedure may affect the viability of the sampled cells. In order to answer this question, we attempted to analyze the physical factors that are involved in aspiration biopsy and their possible influence on cell viability. Particular attention was devoted to the effects of negative pressure.

Presented at the Second International Congress of Exfoliative Cytology, Paris, 1965.

\section{MerHods}

Technique of aspiration biopsy: Fig. 1 illustrates the technique of aspiration biopsy as used at Radiumhemmet. The apparatus consists of an ordinary 22 gauge needle attached to a $10 \mathrm{ml} \mathrm{rec}$ ord syringe of Luer-Lok type. The syringe has a special handle which allows a one-hand grip while biopsy is being made. ${ }^{11}$ Use of the thin needle minimizes admixture of blood. A thicker needle may occasionally have to be substituted, however, if the initial puncture indicates presence of dense, fibrotic tissue. No anaesthesia is used. The skin is wiped over with an antiseptic and the suspected tumour is held with one hand in a position favourable for needle biopsy (fig. 1). When the aspiration has been completed the material in the needle is carefully expressed on to a glass slide. The smears are dried in air at room temperature, after which they are stained with the May-Grünwald-Giemsa stain commonly used in haematology. In some cases of the present series, especially when the aspirate was rich in cells, these slides were supplemented by smears fixed before drying in 50 per cent ether-ethyl alcohol mixture and stained according to Papanicolaou.

Measurement of pressure differences during aspiration biopsy.

An apparatus for registering pressure differences during aspiration biopsy was evolved ${ }^{6} \mathrm{It}$ is shown in figure 2. The apparatus is connected by means of a three-way stopcock to a syringe. The pressurerecording device consists of a conical tube having in its lower part a pressure chamber which connects with the syringe but is separated from the rest of the apparatus by a flexible, light-reflecting diaphragm of stainless steel. This diaphragm is about $0.5 \mathrm{~mm}$ thick. In the upper part of the tube a filament lamp is inserted in such a way that the diaphragm is illuminated from a circular opening in the centre of a photocell, which is shielded from the direct light of the lamp. When a subatmos pheric pressure is produced in the pressure chamber, the diaphragm bends and as a result the light 


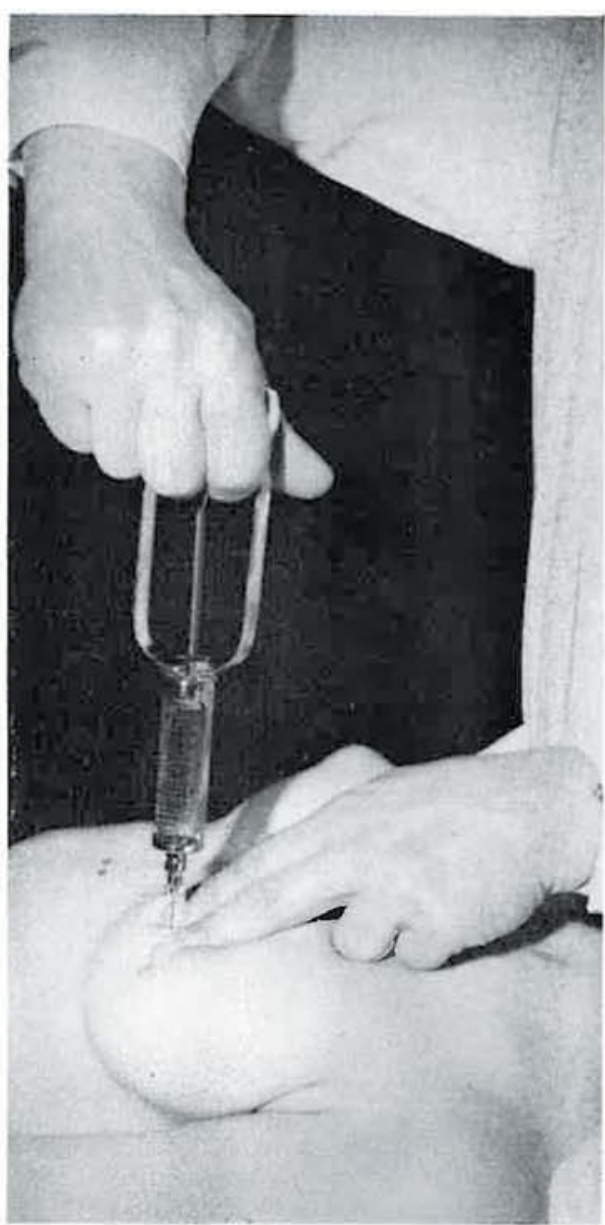

Fic. 1. Aspiration biopsy of a mammary tumour, showing the one-hand grip of the apparatus. The plunger of the syringe is retracted during the aspiration.

from the circular opening is increasingly focused on the photocell (in this case a sclenium cell). From therc the voltage is transmitted to a recorder. When the apparatus has been calibrated against a manometer, pressure differences can readily be calculated.

\section{REsults}

A. Aspiration biopsy of mammary tumours in cytologic diagnosis.

Figure 3 demonstrates the frequency of aspiration biopsy of the female breast at Radiumhemmet between 1955 and 1963. From 1955 through 1962 aspiration biopsy was performed on 2,200 women who came to Radiumhemmet because of suspected mammary tumour. The shaded parts of the columns in figure 2 indicate cases in which surgery was performed after aspiration biopsy and material thus was available for histologic diagnosis. The total of such cases was 1,220 . In the remaining 980 cases ( 44,5 per cent of the total) aspiration biopsy was not followed by surgery. In 22 per cent of this group inoperable carcinoma was clinically and cytologically diagnosed. In the other patients the clinical and cytologic diagnoses were cysts (which were evacuated by the aspiration), mastitis, fibroadenoma, etc

The 1,220 cases in which cytologic and subsequent histologic findings could be compared are presented in table 1 .

In 542 of these cases the histologic report stated benign mammary lesion. Cytologic study of biopsy aspirate had given no indication of malignancy in 86,4 per cent of the histologically benign cases. The cytologic slides showed cellular atypia in a further 10,1 per cent of this group and in the remaining 3,5 per cent there was cytologic suspicion of cancer. No false positive cytologic diagnosis of cancer was made.

In 21 of 27 cases in which the lesion was considered or suspected to be precancerous, cytologic examination of biopsy aspirate had been negative for malignancy. In another case the cytologic report stated cellular atypia. Four lesions were cytologically suspected to be malignant and in one case the cytologic diagnosis was cancer.

The histologic diagnosis was cancer in 645 cases and suspected cancer in 6 cases. In 9,1 per cent of these 651 cases the cytologic report was negative for cancer. As a rule this could be attributed to unsatisfactory specimens of aspirate. In 2 per cent of the histologically demonstrated malignancies the cytologic report indicated cellular atypia. In 14,4 per cent malignancy was cytologically suspected, and in 74,5 per cent a diagnosis of mammary cancer was made from study of the biopsy aspirate. It seems pertinent that of the 485 cases in which cancer was cytologically diagnosed from aspiration biopsy, 30 per cent lacked such obvious clinica? signs of advanced mammary carcinoma as fixation. of skin and muscle and retraction of the nipple.

The results in table 1 may be summarized as follows. The possibility of false positive diagnosis of mammary cancer from aspiration biopsy may be disregarded if the cytologist is fully familiar with the morphology of mammary gland cells in various pathologic conditions. In the series here presented, aspiration biopsy gave false negative results in 11,1 per cent of cases with mammary cancer (12,3 per cent between 1955 and 1961 and 7,9 per cent in 1962). No false positive diagnosis was made. Cytologic diagnosis of mammary cancer 


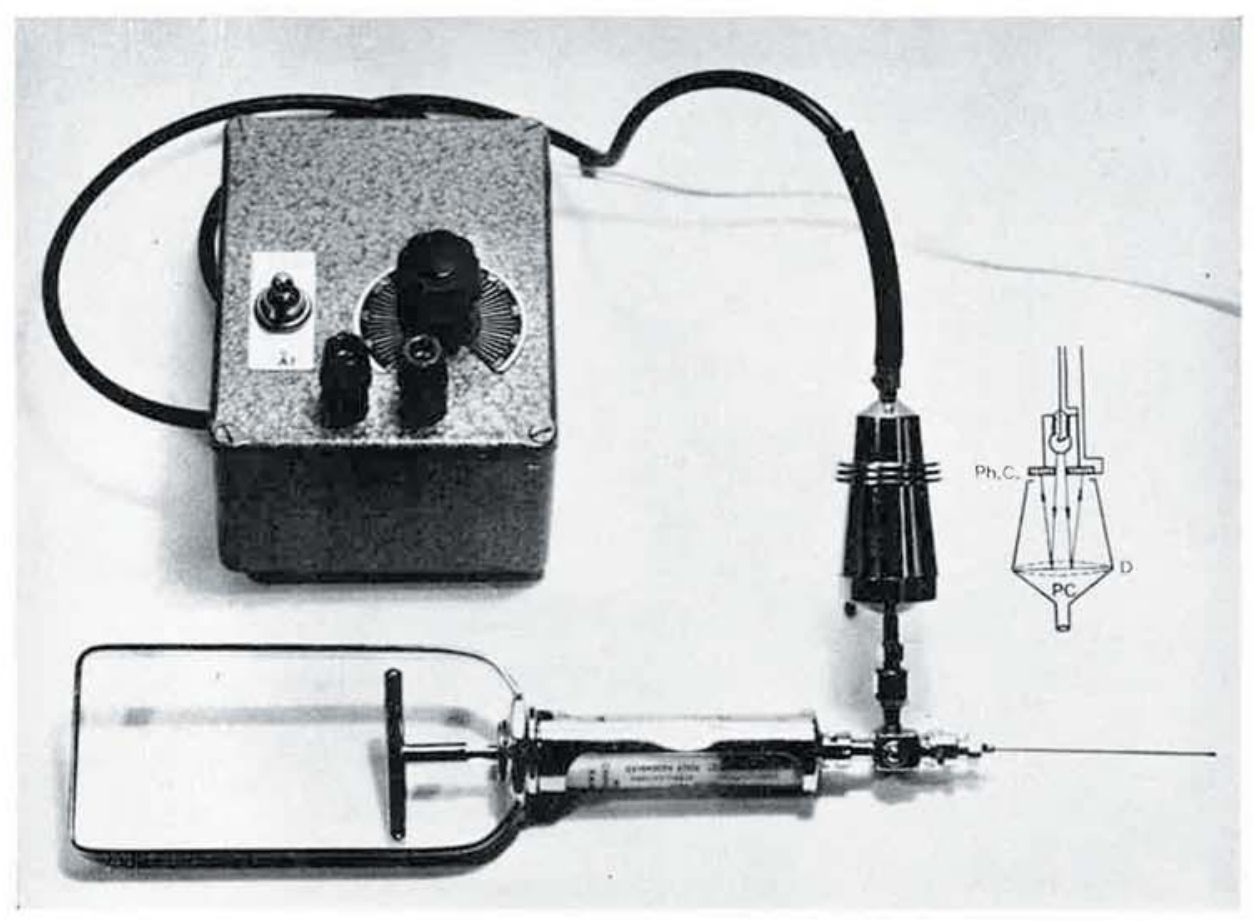

FIg. 2. The pressure gauge connected with the syringe and needle by the three-way stopcock. The pressure chamber (PC) is in communication with the syringe. The chamber is bounded by a flexible diaphragm (D) which reflects light from a filament bulb on to a selenium photocell ( $\mathrm{PhC}$ ). The cell transmits pressure readings to a recorder (shown above the syringe).

is therefore considered at Radiumhemmet to be fully reliable, and operable cases are now referred for radical surgery without prior surgical biopsy.

B. Aspiration biopsy of human tumours in biologic research

Resulis. Figure 4 shows the pressure changes in the syringe during a prolonged aspiration biopsy of a lymph node. The air in the system had first been expelled by filling the pressure chamber, the threeway stopcock and the needle with an anticoagulant (citrate-dextrose solution). The time taken for the biopsy was 29 seconds. During this time the pressure in the syringe was maintained at about $16 \mathrm{~mm}$ $\mathrm{Hg}$. In order to obtain sufficient material, the needle was moved back and forth in the lymph node four or five times during the aspiration. When the sample had been taken, the pressure in the syringe was allowed to return to atmospheric equilibrium by releasing the plunger to its original position before the needle was withdrawn from the lymph node. The graph illustrates how the pres- sure in the syringe normalized during this manipulation.

In the experiment illustrated in figure 4 , the pressure differences arising in the needle during aspiration biopsy amounted to about $740 \mathrm{~mm} \mathrm{Hg}$. These differences represent maximal values when the described apparatus is used for aspiration biopsy. The pressure changes may be somewhat less if the needle contains air instead of anticoagulant solution during aspiration. A 22 gauge needle, such as we used for aspiration biopsy of mammary tumours, can accommodate about $0,04 \mathrm{ml}$ of air. The influence of this or larger volumes of air on the pressure in the syringe can readily be deduced from Boyle-Mariotte's law. Thus, if for some reason it is desirable to minimize differences in pressure, this can be done by starting the aspiration biopsy with a known volume of air in the system.

Subsequent investigations concerned the extent to which pressure differences of the mentioned order may influence the viability and proliferation rates of the aspirated cells. It was found that pres- 
sure differences similar to those created during aspiration biopsy had no apparent effect on the viability of HeLa and bone-marrow cells in suspension. ${ }^{22}$ These cells remained impermeable to the eosin and lissamine-green dyes which are commonly used in testing the viability of human tumour cells. The proliferation rates of $\mathrm{HeLa}$ and bone-marrow cells were likewise unchanged by the negative pressures. Proliferation of HeLa cells was studied in tissue cultures and proliferation of marrow cells in transplantation experiments on lethally irradiated mice.

When cells in the living organism are subjected to such negative pressures, however, the situation

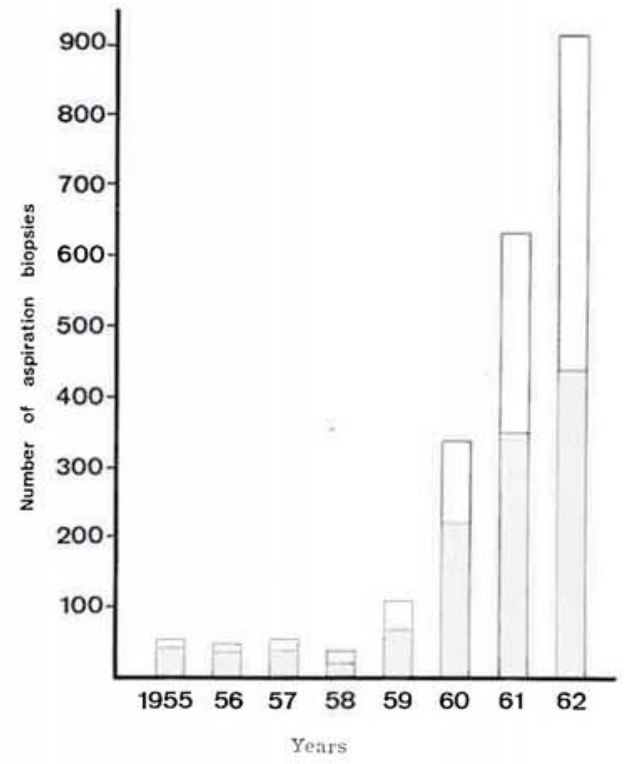

Fic. 3. Frequency of aspiration biopsy in mammary tumour diagnosis at Radiumhemmet 1955-1962. The shaded parts of the columns denote cases in which surgery was subsequently performed. presents some additional factors. Forces of adhesion and, especially as regards epithelial cells, intercellular forces of cohesion then maintain the position of the cells in relation to their surroundings. We must therefore consider to what extent the breakdown of the adhesion and cohesion forces during aspiration biopsy affects the viability of the sampled cells. In order to investigate this question we performed aspiration biopsies on rat spleens at various negative pressures and recorded the viability of sampled cells. The cell viability was determined with the trypan blue permeability test $^{21}$ and the trypsin digestion test. ${ }^{7}$ The results are presented in figure 5 (compiled in collabora. tion with S. Plesničar and $\AA$. Sigurdson). When the pressure difference in the needle during aspiration biopsy was about $80 \mathrm{~mm} \mathrm{Hg}, 70$ to $80 \mathrm{per}$ cent viable lymph cells were obtained in aspirates from the spleen. Increase of the negative pressure from 80 to $740 \mathrm{~mm} \mathrm{Hg}$ had some slight effect on cell viability.

Epithelial cells in vivo have not yet been studied with respect to possible influence of needling and of negative pressures. That viable carcinoma cells can be obtained by aspiration biopsy from mammary tumours can be deduced from figures 6 and 7 , however. Figure 6 shows cell viability rates in aspirates from 29 primary carcinomas of the breast. In sampling the cell material the needle was moved back and forth in the tumour four or five times and in some cases was inserted into different areas of the tumour. Cell viability was determined with the eosin dye permeability test. The cases are arranged in order of frequency of viable cells. It is seen that aspirates from some of these mammary carcinomas contained only about 10 per cent viable cells and that the highest values were in the range 60 to 80 per cent.

The effect of trypsin digestion on aspirated mammary carcinoma cells is illustrated in figure 7. Figure 7 shows carcinoma cells from an aspirate after suspension for 30 minutes in Hank's solution containing 0,35 per cent trypsin. Many of the aspiraedt mammary carcinoma cells resisted di-

TABle 1. Cytologic Findings in 1220 Cases with Histologically Diagnosed Mammary Gland Lesion

\begin{tabular}{|c|c|c|c|c|}
\hline \multirow{3}{*}{ Cytologic findings } & \multicolumn{3}{|c|}{ Histologic findings } & \multirow[b]{2}{*}{ Total } \\
\hline & Benign & Precancerous lesion & Cancer & \\
\hline & 342 & 27 & $651^{*}$ & 1220 \\
\hline $\begin{array}{l}\text { Benign or unsatis- } \\
\text { factory specimen }\end{array}$ & $468(86.4 \%)$ & $21(77.8 \%)$ & $59(9.1 \%)$ & 548 \\
\hline Cellular atypia & $55(10.1 \%)$ & $1(3.7 \%)$ & $13(2.0 \%)$ & 69 \\
\hline $\begin{array}{l}\text { Suspectedly malig- } \\
\text { nant }\end{array}$ & $19(3.5 \%)$ & $4(14.8 \%)$ & $94(14.4 \%)$ & 117 \\
\hline Cancer & 0 & $1(3.7 \%)$ & $485(74.5 \%)$ & 486 \\
\hline
\end{tabular}

* In 6 cases malignancy was only suspected. 


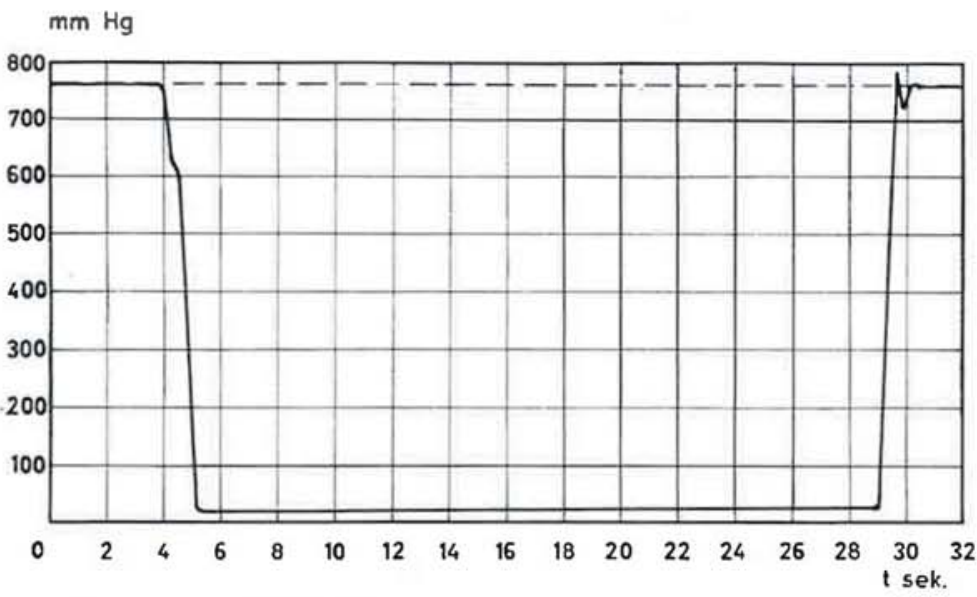

FIc. 4. Pressure differences in the syringe during aspiration biopsy of a lymph node.

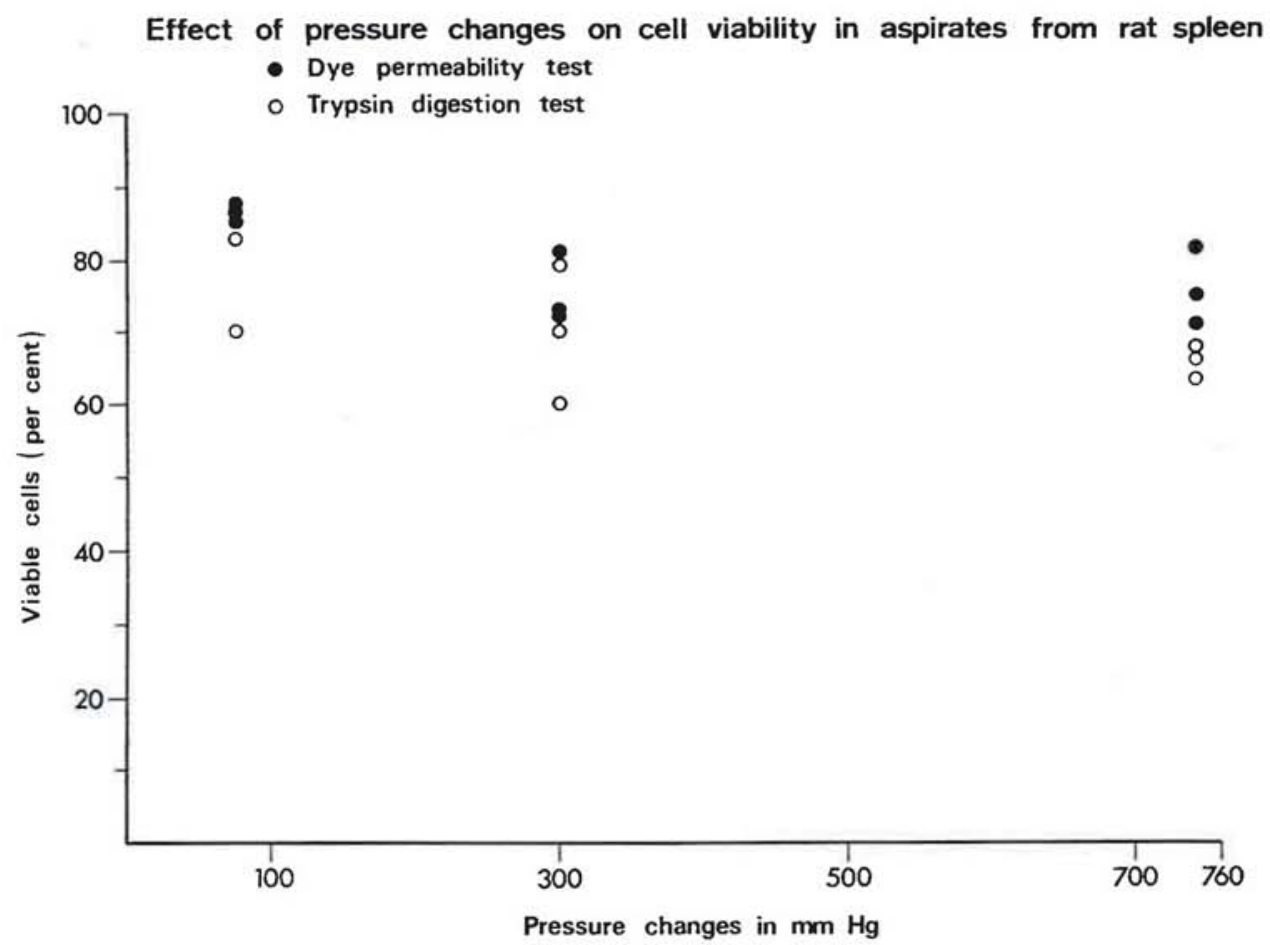

FIG. 5. Cell viability in aspirates from rat spleen correlated with pressure changes created in the syringe during biopsy.

gestion by trypsin and must therefore be considered viable (7). Remnants of some digested cells are also seen.

The data presented in figures 5,6 and 7 permit the conclusion that viable cells can be obtained by aspiration biopsy and that consequently the method is suitable for sampling cellular material from human tumours for biologic study. 


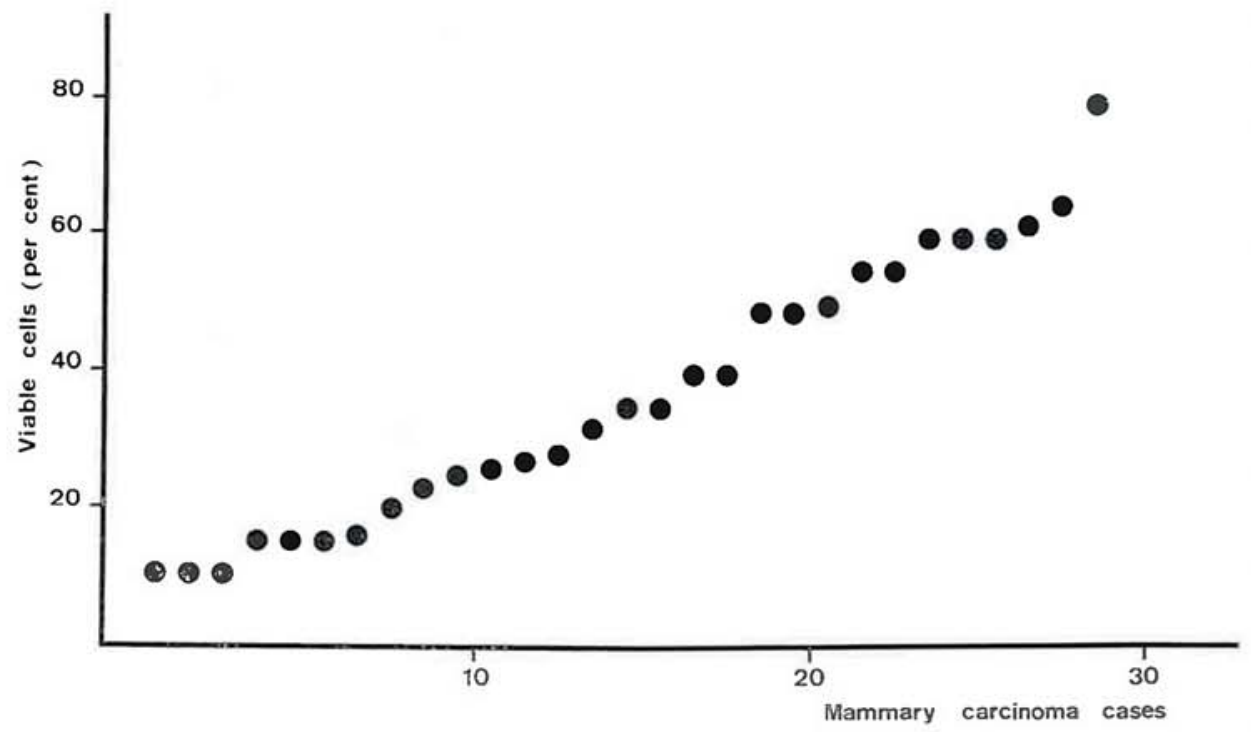

FIG. 6. Percentages of viable cells in aspirates from 29 primary carcinomas of the breast. The cases are arranged in order of frequency of viable cells. (Eosin dyc permeability test).

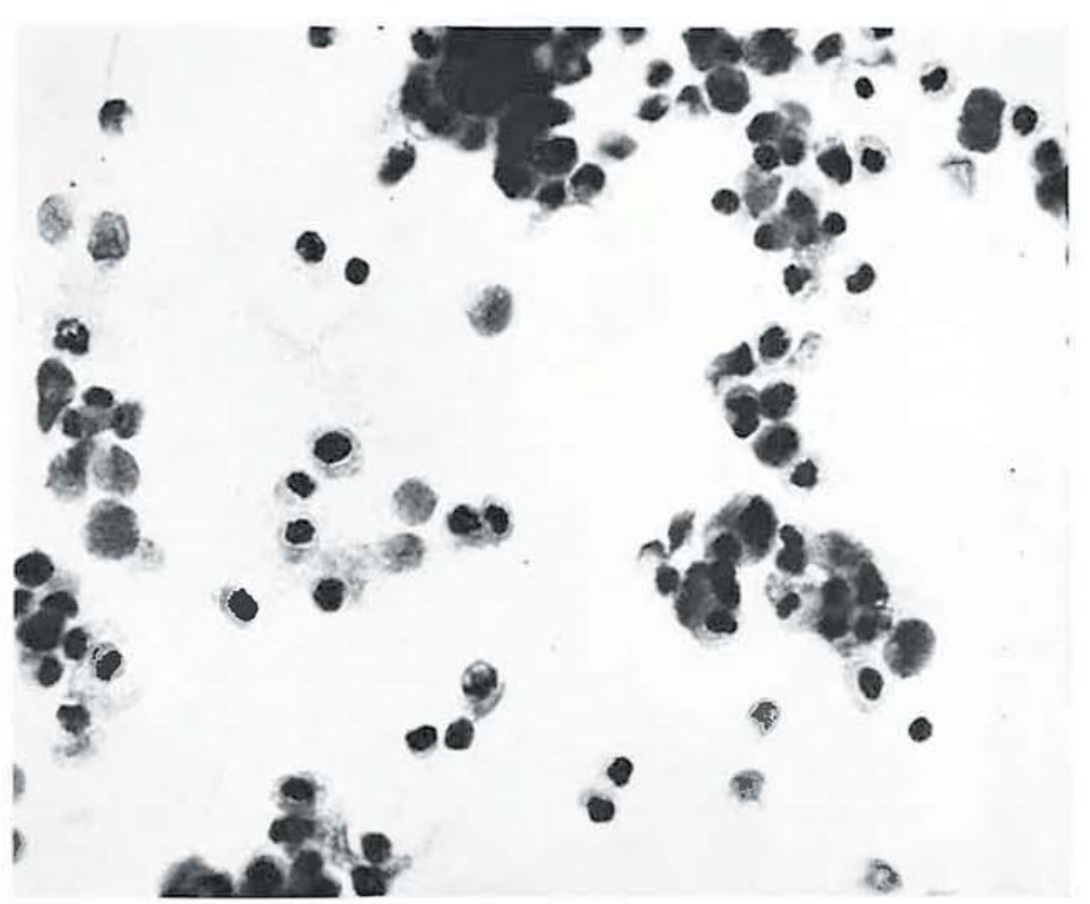

Fig. 7. Aspirated mammary carcinoma cells after suspension in Hank's solution containing 0.35 per cent trypsin for 30 minutes. In addition to viable cells which had resisted trypsin digestion, remnants of digested cells can be seen. 


\section{SuMMary}

During the eight-year period 1955-1962, aspiration biopsy of the breast was performed on 2,200 patients who attended Radiumhemmet in Stockholm because of palpable mammary lesions. In 980 cases the aspiration biopsy was not followed by surgery. The clinical and cytologic diagnoses in these cases were inoperable carcinoma (22 per cent), cysts which were evacuated by the aspiration biopsy, mastitis, etc.

In 1,200 cases the cytologic findings could be compared with histologic reports after surgery. This comparison illustrates the usefulness of cytologic examination of biopsy aspirates in the diagnosis of mammary tumours.

Cellular aspirates from mammary tumours were used also for cytochemical studies and for work on tissue cultures, including determination of the viability of cancer cell populations during various forms of treatment. When biopsy aspirates are used for biologic studies of tumour cells, an important question is whether or not the aspiration procedure as such can influence the viability of the sampled cells. Physical factors involved in the technique of aspiration biopsy were therefore analyzed in this respect, with special emphasis on the effect of pressure differences.

\section{REFERENCES}

1. Appaix, A., Bonneau, H. et Sommer, D. La cytologie des tumeurs des glandes salivaires. Pr. Méd., 67 : 600-602, 1959.

2. BERG, J. W. The aspiration biopsy smear. In Koss, L., Diagnostic Cytology and its Histopathologic Bases, Lippincott, Philadelphia, 1961.

3. Bonneav, H., Sommer, D. et De The, G. Étude critique de la cytologie tumorale par ponction a l'aiguille fine. Pr. Méd., 68: 909-912, 1960.

4. Cardozo, P. L. Clinical Cytology, L. Stafleu, Leyden, 1954.

5. Cornillot, M. et Verhaeghe, M. Données cytologiques dans les ponctions de tumeurs du sein. Path. Biol., 7: 793-802, 1959.

6. Criborn, C. O., Franzín, S., Unsgaard, B. and ZaficeK, J. Studies on the effect of aspiration biopsy on the viability of aspirated cells. Scand. J. Haemat., 1: 272-279, 1964.

7. DE LUCA, C. The use of trypsin for the determination of cellular viability. Exp. Cell. Res., 40: 186-188, 1965.

8. Einhors, J. and FranzÉN, S. Thin-needle biopsy in the diagnosis of thyroid disease. Acta Radiol., Stockholm, 58: 321-336, 1962.

9. Esposti, P. L., Estborn, B. and Zajicex, J. Determination of acid phosphatase activity in cells of prostatic tumors. Naturc 188: 663-664, 1960.
10. Espostr, P. L. and Zajrcek, J. Morphologic and cytochemical studies in cancer of the prostate. The Swedish Cancer Society, Yearbook 3, Almqvist \& Wiksell, Uppsala, 1963.

11. Franzén, S., Giertz, G., and Zajicex, J. Cytological diagnosis of prostatic tumors by transrectal aspiration biopsy: a preliminary report. Brit. J. Urol.,32: 193-196, 1960.

12. Godwin, J. T. Aspiration biopsy: Technique and application. Ann. N. Y. Acad. Sci., 63: 1348$1373,1956$.

13. GRUNZE, H. A critical review and evaluation of cytodiagnosis in chest diseases. Acta Cytol., 4: 175-198, 1960 .

14. Johansson, B. and Zajicek, J.' Sampling of cell material from human tumours by aspiration biopsy. Nature, 200: 1333-1334, 1963.

15. Marsan, C. and Bertini, B. La place des méthodes cytologiques dans le diagnostic des tumeurs du sein. Path. Biol. 8: 343-366, 1960.

16. Martin, H. E. and Ellis, E. B. Biopsy by needle puncture and aspiration. Ann. Surg., 92: 169$181,1930$.

17. Martin, H. E. and Ellis, E. B. Aspiration biopsy. Surg. Gynec, Obstet, 59: 578-589, 1934.

18. Mavec, P., Eneroth, C-M., Franzén, S., Moberger, G. and ZajiceK, J. Aspiration biopsy of salivary gland tumours. I. Correlation of cytologic reports from 652 aspiration biopsies with clinical and histological findings. Acta Otolaryng. 58: 471-484, 1964.

19. Pavlovsky, A. La Puncion ganglionar. Lopez, Buenos Aires, 1934.

20. Robbins, G. F., Brothers III, J. H., Eberhatr, W. F. and QUAN, S. Is aspiration biopsy of breast cancer dangerous to the patient? Cancer, $7: 774-778,1954$.

21. Tennant, J. R. Evaluation of the trypan bluc technique for determination of cell viability. Transplantation 2: 685-694, 1964.

22. Unsgaard, B. and Zajicek, J. Data to be published.

23. Vozely, M. and ZajiceK, J. Quantitative determination of enzymic activities in cells and in extracellular fluid aspirated from human tumors by needle biopsy. Experientia, 18: 149, 1962.

24. ZAJDELA, A. Valeur ct intérêt du diagnostic cytologique dans les tumeurs du sein par ponction. Étude de 600 cas confrontés cytologiquement et histologiquement. Arch. Anat. Path., 11: 85-87, 1963.

25. Zajicek, J., Esposit, P. L. and VOzel.J, M. Quantitative determination of enzymic activities in cells obtained from human carcinomas by aspiration biopsy. Proc. First Int. Congr. Ex. Cytol., Lippincott, Philadelphia, 1962. 


\section{References}

1 Zajicek J, Franzén S, Jakobsson P, Rubio C, Unsgaard B: Aspiration biopsy of mammary tumors in diagnosis and research - a critical review of 2,200 cases. Acta Cytol 1967;11: 169-175.

2 Franzén S, Zajicek J: Aspiration biopsy in diagnosis of palpable lesions of the breast. Critical review of 3,479 consecutive biopsies. Acta Radiol Ther Phys Biol 1968;7:241-262.

3 Zajicek J: Cytologic study of punctates in mammary gland diagnosis (in German). Schweiz Med Wochenschr 1969;99:12711273.

4 Kreuzer G, Zajicek J: Cytologic diagnosis of mammary tumors from aspiration biopsy smears. Acta Cytol 1972;16:249-252.

5 Löfgren L, Skoog L, von Schoultz, Tani E, Isaksson E, Fernstad R, Carlström K, von Schoultz B: Hormone receptor status in breast cancer - a comparison between surgical specimens and fine needle aspiration biopsies. Cytopathology 2003;14:136-142.
6 Masood S: Assessment of prognostic factors in breast fine needle aspirates. Am J Clin Pathol 200;113(5 suppl 1):584-596.

7 Zajicek J: Sampling of cells from human tumors by aspiration biopsy for diagnosis and research. Eur J Cancer 1965;1:253-258.

8 Esposti PL, Estborn B, Zajicek J: Determination of acid phosphatase activity in cells of prostatic tumours. Nature 1960;188:663-664.

9 Nordenskjöld B, Löwhagen T, Westerberg H, Zajicek J: ${ }^{3} \mathrm{H}$-Thymidine incorporation into mammary carcinoma cells obtained by needle aspiration before and during endocrine therapy. Acta Cytol 1976;20:137-143.
10 Azavedo E, Baral E, Skoog L: Immunohistochemical analysis in cells obtained by fine needle aspiration from human mammary carcinomas. Anticancer Res 1986;6:263-266.

11 Tani EM, Christensson B, Porwit A, Skoog L: Immunocytochemical analysis and cytomorphological diagnosis on fine needle aspirates of lymphoproliferative diseases. Acta Cytol 1988;32:209-215.

12 Skoog L, Rutqvist LE, Wilking N: Analysis of hormone receptors and proliferation fraction in fine-needle aspirates from primary breast carcinomas during chemotherapy or tamoxifen treatment. Acta Oncol 1992;31:139-141.

13 Billgren A-M, Rutquist LE, Tani E, Wilking N, Fornander T, Skoog L: Proliferating fraction during neo adjuvant chemotherapy of primary breast cancer in relation to objective local response and relapse-free survival. Acta Oncol 1999;38:597-601. 